Pacific Journal of Mathematics

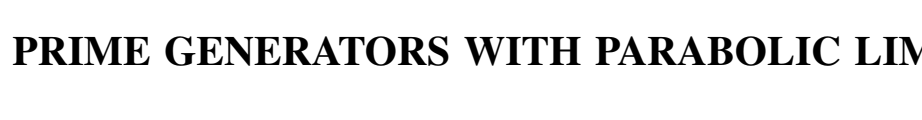




\title{
PRIME GENERATORS WITH PARABOLIC LIMITS
}

\author{
JoHN HARRIS AND Olga Higgins
}

The prime generating properties of the formula

$$
F=\frac{A X^{2}+A B X Y+C Y^{2}}{(A, Y)}, \quad(X, Y)=1
$$

are developed by way of three theorems. Theorem $I$ is a prime test for F, Theorem II will factor a composite $F$, and Theorem III establishes parabolic limits; within these limits $F$ is always prime.

In the 18th century Leonhard Euler and A. M. Legendre found several "prime generating" polynomials. Euler's famous formula $X^{2}+X+41$ takes prime values for every integral value of $x$ from 0 to 39, and Legendre's formula $2 x^{2}+29$ does almost as well, taking prime values for every integral value of $x$ from 0 to 28. These and many other expressions that have been found since have coefficients of the form $[A, A B, C]$, with $B=0$ or 1 and $C$ a prime.

After numerous experiments with two variables we have chosen

$$
F=\frac{A X^{2}+A B X Y+C Y^{2}}{E}, \quad E=(A, Y),(X, Y)=1
$$

as our basic "prime generating" formula. The coefficients $A, B$ and

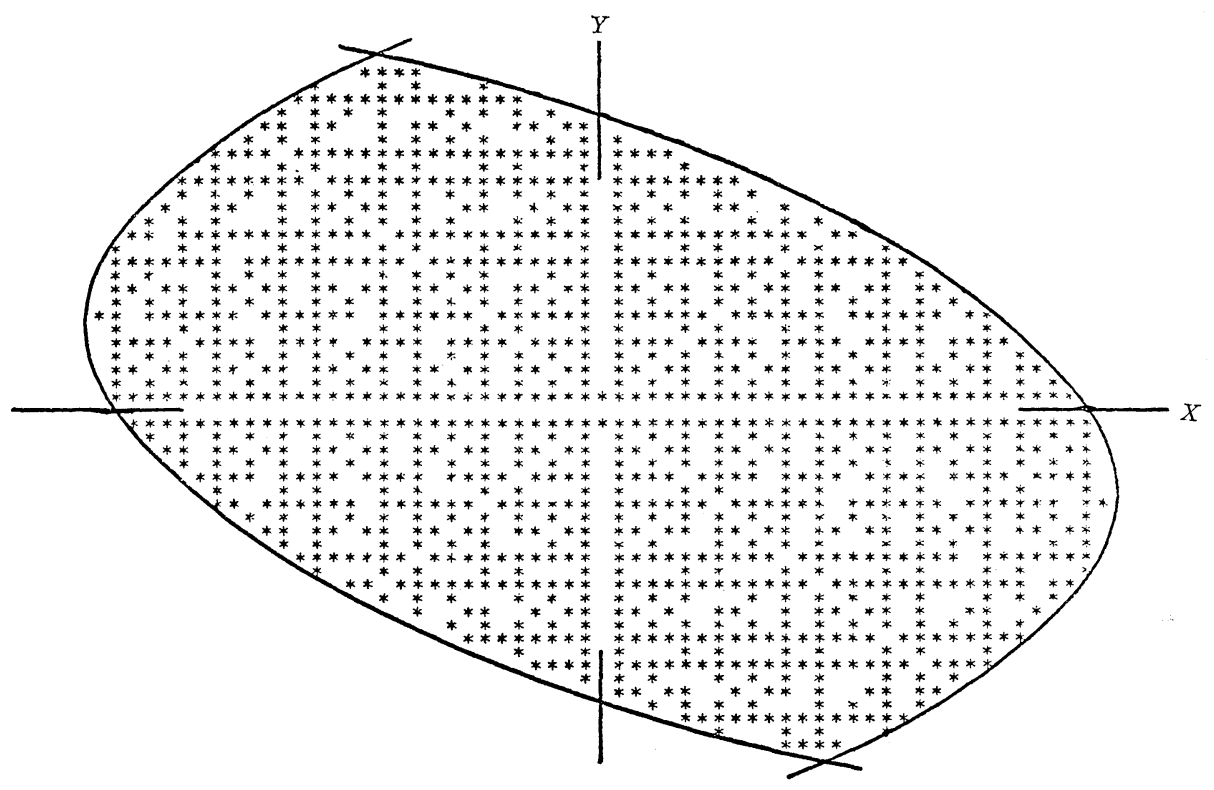

FIGURE 1 
$C$ are to be chosen from Table $I$, and then $F$ is a function of the two variables $X$ and $Y$. That this can be a very effective prime generator is shown by Fig. 1, where all of the dots represent primes; see Example 3. Figure 1 shows the typical dot pattern which is due to the requirement $(X, Y)=1 . \quad F$ is defined differently in the text by the definitions of $\S 2$, but the mathematical result is the same as shown in the proof of Theorem III.

The three theorems presented in this paper answer some of the more interesting questions about our formula. Theorem $I$ is a prime test that determines whether $F$ is prime or composite. Theoretically it will test numbers of any size, see Example 1. Theorem II will factor a number found composite by Theorem I. Theorem III gives the prime generating limits of our formula; the parabolic limits inside of which there are no composite values of $F$. Fig. 1 shows how these limits are established by intersecting parabolas. The nature of $F$ outside the limits is not shown in Fig. 1; there are primes, which could be shown by dots, and composites, which could be represented by some other symbol.

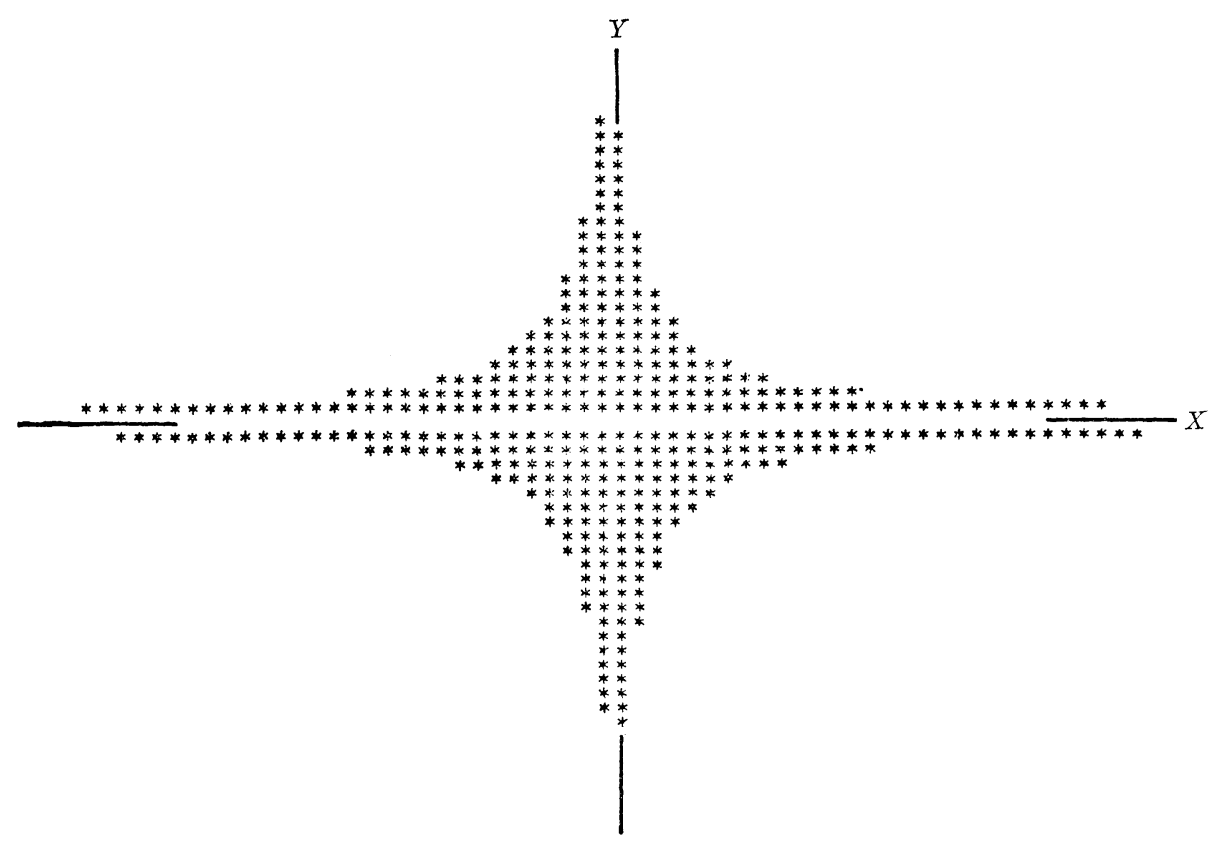

FIgURE 2

Example 4 and Fig. 2 present a function that is perhaps more in the spirit of Euler's original discovery; the function has prime values within the limits for consecutive integral values of both variables. In this case the limits are hyperbolas. 
2. Definitions and two theorems. Let $A, B$ and $C$ be any integers subject to the following conditions: [See Table I.]

\section{TABLE I}

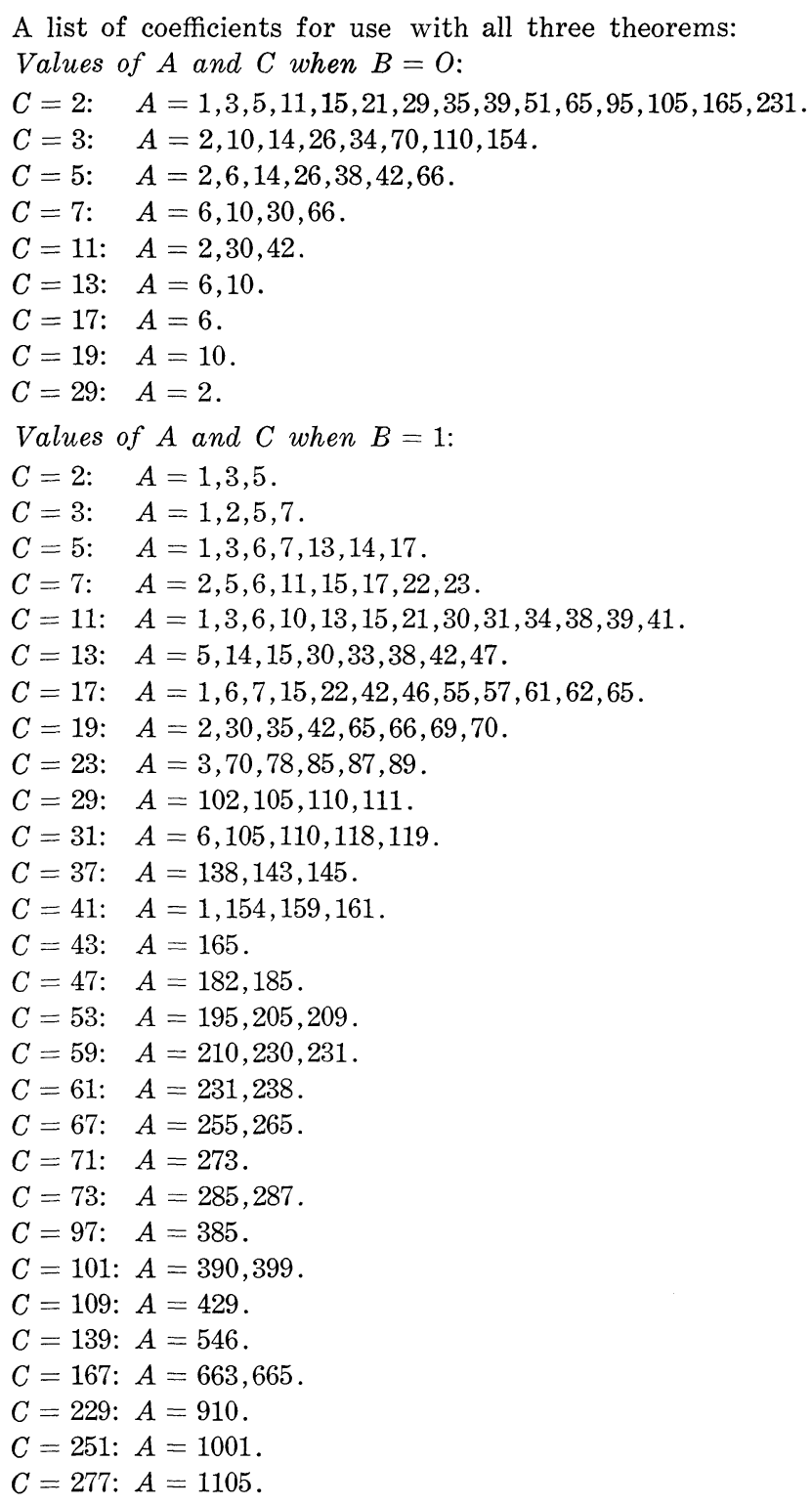

C1. $A>0, B=0$ or $B=1, C$ is a prime.

C2. $A C$ has no square factors $>1$.

C3. $4 C-A B^{2}>2$.

C4. Every positive integral binary quadratic form with the discriminant $-D$ [see $D 1$ below] must be equivalent to one of the forms $[A / e, A B, e C]$, where $e$ is any positive divisor of $A$. 


\section{DEFINITIONS.}

D1. Let $D=4 A C-A^{2} B^{2}$; then $D>2$ by $\mathrm{C} 1$ and $\mathrm{C} 3$.

D2. Let $E$ be a positive divisor of $A$.

D3. Let $X$ and $y$ be any two integers such that $(X A / E, E y)=1$ and $y \neq 0$.

D4. Let $F=(A / E) X^{2}+A B X y+E C y^{2}$.

D5. Let $Y=E y$, so $Y \neq 0$; and let $Z=2 A X+A B Y$.

D6. Let $I$ be any integer and let $N=-D I^{2}+2 Z I+Y^{2}$.

Theorem I. $F$ is a prime if and only if $N$ is never a square when $I \neq 0$; this can be determined in a finite number of steps.

THEOREM II. When $N=n^{2}$ with $I \neq 0$, a proper divisor $M>1$ of $F$ can be found as follows: Let $L=A I, H=(n-B L-Y) / 2$, $G=(H, L), R=H / G, S=L / G, Q=(A, S)$, and then: $M=\left(A R^{2}+\right.$ $\left.A B R S+C S^{2}\right) / Q$.

3. Outline of the proofs. First we show that $F>1$, so $F$ is either prime or composite; next, when $F$ is composite, nonzero integers $W$ and $K$ are found such that $N$ is a square when $I=K W$; finally, we prove Theorem II, so if $N$ is a square with $I \neq 0$ then $F$ must be composite. That only a finite number of values of $I$ can make $N$ positive or zero [and so possibly a square] follows from D1 and D6. When these facts are combined they prove Theorem I.

4. Preliminary Theory. $[F>1,(F, A)=1$, and the form of a divisor of $F$.]

The proof that $F>1$ : From D3, D4 and D5,

$$
E F=A X^{2}+A B X Y+C Y^{2},
$$$$
(X, Y)=1
$$

so $4 A E F=(2 A X+A B Y)^{2}+\left(4 A C-A^{2} B^{2}\right) Y^{2}$, which reduces to

$$
4 F=(A / E)(2 X+B Y)^{2}+\left(4 C-A B^{2}\right)\left(Y^{2} / E\right) .
$$

$A / E$ and $Y^{2} / E$ are positive integers and $4 C-A B^{2}>2$ by $\mathrm{C} 3$, so $F>0$, and if $F=1$ then $4 C-A B^{2}=3$ or 4 . Since $C>1$ by $C 1$ we have $B=1, Y^{2} / E=1, Y^{2}=1, E=1,4 C-A=4-A(2 X \pm 1)^{2}=3$ or 4 ; then $A=1$ and $4 C-A=3$ or 4 , which is impossible. Hence $F>1$.

The proof that $(F, A)=1$ : Let a prime $p$ divide both $F$ and $A$. Then $p \mid Y$ by $\mathrm{C} 2$ and (1), which implies $X \neq 0$ and $p \nmid X$ by $(X, Y)=1$. $(A / E, y)=1$ from D3 so $(A, Y)=E$ and $p \mid E$; but this leads to the 
impossible conclusion that $p^{2}$ divides every term of (1) except $A X^{2}$ [see C2]. Hence $(F, A)=1$.

Definition of P. Let $P$ be any prime divisor of $F$.

Then since $P \mid E F$ which is properly represented by $[A, A B, C]$ as shown by (1), a form with the discriminant $-D$, it follows by Lagrange's well known theorem that $P$ can also be represented by a form with the discriminant $-D$. Then the fact that equivalent forms represent the same numbers, and $\mathrm{C} 4$, combine to show that $P$ can be represented by $[A / J, A B, J C]$, where $J$ is a positive divisor of $A$. Integers $u$ and $W$ can therefore be found such that

$$
P=(A / J) u^{2}+A B u W+J C W^{2} \text {. [Compare to D4.] }
$$

Then we also have:

$$
P=(A / J)(-u-B J W)^{2}+A B(-u-B J W) W+J C W^{2},
$$

since by eliminating $P$ between (2) and (3) we arrive at an identity. Also an identity: $\left(A X^{2}+A B X Y+C Y^{2}\right) J W^{2}-\left(A / J u^{2}+A B u W+\right.$ $\left.J C W^{2}\right) Y^{2}=(A / J)(J W X-u Y)(J W X+u Y+B J W Y)$, so from (1) and (2):

$$
\text { (4) } E F J W^{2}-P Y^{2}=(A / J)(J W X-u Y)(J W X+u Y+B J W Y) \text {, }
$$

where $A / J$ is integral. It follows from $(F, A)=1$ that $(P, A)=1$, so from (4): $\mathrm{P}$ divides either $J W X-u Y$ or $J W X+u Y+B J W Y$, or both. If $P$ divides $J W X-u Y$, let $U=u$; if not, let $U=-u-$ $B J W . P$ divides $J W X-U Y$ in both cases, so let

$$
K=\frac{J W X-U Y}{P}
$$

then $K$ is always integral. By (2) or (3),

$$
P=(A / J) U^{2}+A B U W+J C W^{2} .
$$

5. The proof that a nonzero value of $I, I=K W$, makes $N$ a square when $\mathrm{F}$ is composite. Let $F$ be composite. Then $X \neq 0$, since if $X=0$ we have $Y^{2}=1, y^{2}=E=1, F=C$. Also, $W \neq 0$ by $(6),(P, A)=1$, and $P \neq 1 . \quad[P \neq 1$ because it is prime.] Finally, $(U, J W)=1$, because if $U$ and $J$ have a common prime divisor it must divide both $P$ [by (6)] and $A$, contradicting $(P, A)=1$; while if a prime divides both $U$ and $W$, its square divides the prime $P$ by (6).

Now suppose that $K=0$; then $J W X=U Y$ by (5), where 
$J W X Y \neq 0$; hence $U \neq 0 . \quad$ Then $(X, Y)=1, \quad(U, J W)=1$ and $J W X=U Y$ shows that $X \mid U$ and $U \mid X$, so $X=U$ and $Y=J W$ or $X=-U$ and $Y=-J W$. In both cases, $E F=J P$ by (1) and (6), and since $(F P, E J)=1[E$ and $J$ divide $A]$, we conclude that $F=P$, a prime. Hence $K W \neq 0$ when $F$ is composite.

Let $I=K W$ with $F$ composite, so $I \neq 0$; eliminating $P$ between (5) and (6) and multiplying by $\left(4 A K^{2}\right) / J$, we get:

$$
(2 A K U / J)^{2}+2(2 A K U / J) A B I+4 A C I^{2}=4 A X I-4 A K U Y / J,
$$

which reduces to

$$
N=(2 A K U / J+A B I+Y)^{2},
$$

by $\mathrm{D} 1, \mathrm{D} 5$ and $\mathrm{D} 6$. Since $J \mid A, N$ is a square.

6. The proof of Theorem I and Theorem II. From $N=n^{2}$ and D6:

$$
n^{2}=-D I^{2}+2 Z I+Y^{2}
$$

New Definitions.

D7. $L=A I$.

D8. $H=(n-B L-Y) / 2$,

D9. $G=(H, L)$,

D10. $R=H / G$,

D11. $S=L / G$,

D12. $Q=(A, S)$,

$$
\begin{aligned}
& h=(-n-B L-Y) / 2 . \\
& g=(h, L) . \\
& r=h / g . \\
& s=L / g .
\end{aligned}
$$

D13. $M=\left(A R^{2}+A B R S+C S^{2}\right) / Q, \quad m=\left(A r^{2}+A B r s+C s^{2}\right) / q$.

Let $n$ be integral with $N=n^{2}$ and with $I \neq 0$. Then $L \neq 0$, $S \neq 0$ and $s \neq 0.2 H$ and $2 h$ are integral by $\mathrm{D} 8$, they have an even product $(2 H)(2 h)=4 L(C I-X)$ by D8, D7; and (8), D1 and D5. Also, $2 H-2 h=2 n$ by $\mathrm{D} 8$, so $2 H$ and $2 h$ have an even difference and are both odd or both even; with an even product, they must be even. Hence $H$ and $h$ are integral. $H h=L(C I-X)$, so $L$ divides Hh. From (1), D1 and D5,

$$
4 A E F=Z^{2}+D Y^{2},
$$

and there are similar formulas for $M$ and $m$ :

(10) $4 A Q M=(2 A R+A B S)^{2}+D S^{2}, \quad 4 A q m=(2 A r+A B s)^{2}+D s^{2}$.

$2 R+B S=(2 H+B L) / G=(n-Y) / G$ by D10, D11 and D8, and similarly, $2 r+B s=(-n-Y) / g . \quad S=A I / G$ and $s=A I / g$, so from (10), $4 A Q M G^{2}=A^{2}\left([n-Y]^{2}+D I^{2}\right)$ and $4 A q m g^{2}=A^{2}\left([-n-Y]^{2}+\right.$ 
$\left.D I^{2}\right)$. Hence, $16 Q q M m G^{2} g^{2}=A^{2}\left(4 Z^{2} I^{2}+4 D I^{2} Y^{2}\right)=4 A^{2} I^{2}(4 A E F)$ by (8) and (9), so

$$
\left(\frac{G g}{L}\right)^{2} Q q M m=A E F \text {. }
$$

$L \mid H h ; G=(H, L)$; and $g=(h, L)$. Let $p$ be a prime divisor of $L$, and let the symbol " $p(a)$ " represent the highest power of $p$ which divides $a$. If $p(H) \geqq p(L)$ or $p(h) \geqq p(L)$, then $p(G)=p(L)$ or $p(g)=p(L)$ and $p(G g) \geqq p(L)$. In the remaining case, both $p(H)$ and $p(h)$ are less than $p(L)$, so $p(G)=p(H)$ and $p(g)=p(h)$, and then $p(G g)=p(H h) \geqq p(L)$. In all cases the highest power of $P$ which divides $L$ also divides $G g$, and so $L$ divides $G g$.

The proof that $M$ is a proper divisor of $F$. In view of (11) and the last result, we need only show that $M>1, m>1$, and $(M m, A E)=1$. From D9, D10 and D11, we have $(R, S)=1$. Compare this to $(X, Y)=1 ; Q M=A R^{2}+A B R S+C S^{2}$ to $(1) ;$ and $Q=(A, S)$ to $E=(A, Y)$. Also note $S \neq 0$ and $Y \neq 0$; clearly the substitution of $R, S$ and $Q$ for $X, Y$ and $E$ converts $F$ into $M$. In fact, $M$ is one of the numbers $F$, but not the one of which $M$ is a divisor. It follows that $M>1,(M, A)=1$, and by similar reasoning, $m>1$ and $(m, A)=1$. Since $E \mid A$, we have $(M m, A E)=1$, and the proof that $M$ is a proper divisor of $F$ is complete. This proves Theorem II. The proof of Theorem $I$ is now also complete by the reasoning given in "outline of the proofs".

The number of values of $I$ for which $N$ needs to be tested is approximately $(4 \sqrt{A E F}) / D$, so $D / \sqrt{A E}$ should be large for an efficient test. Of all the values given in Table $I, A=210, B=1, C=59$, $E=1$ gives the largest, with $D / V \overline{A E}=376$.

Example 1. Let $A=B=1, C=41$. Then $E=1, Y=y$, and $F=X^{2}+X Y+41 Y^{2}$. Let $X=1000$ and $Y=1$. Then

$$
F=1,001,041 \text {, and } N=-163 I^{2}+4002 I+1 \text {. }
$$

$N$ is negative for negative $I$ and for $I>24$, so we test the 24 values of $N$ given by $I=1,2,3, \cdots, 24$. We get $N=3840,7353,10540$, etc., and find no squares, so $F$ is a prime. [See Theorem I.]

Example 2. Let $A=6, B=1, C=31$; these values can be found in Table I. Let $E=2, X=423, y=19$, then $(X A / E, E y)=1$ as required by $\mathrm{D} 3$, and $F=3(423)^{2}+6(423)(19)+62(19)^{2}=607391$; and $F$ is composite, because for $I=3$ we find $N=(164)^{2}$. By Theorem 
II we now have: $n=164, L=18, H=54, G=18, R=3, S=1$, $Q=1$, and $M=103$. The factors of $F$ are 103 and 5897 .

\section{Theorem III and its proof.}

Theorem III. Define $A, B, C$ and $D$ as before, let $X$ and $Y$ be any two relatively prime integers such that the following limits are satisfied:

$$
D-Y^{2}>|4 A X+2 A B Y|
$$

and let

$$
F=\frac{A X^{2}+A B X Y+C Y^{2}}{(A, Y)} .
$$

Then $F$ is a prime when $Y \neq 0$.

Proof. Let $E=(A, Y)$ and let $y=Y / E$, then from $(A / E, E)=1$, $(A / E, y)=1$, and $(X, E y)=1$, we find $(X A / E, E y)=1$ as in D3. Also, $F=(A / E) X^{2}+A B X y+E C y^{2}$, and the preliminary requirements of Theorem I are satisfied. By D5 and (12), $D-Y^{2}<2|Z|$. Then by D6, $N$ is negative for $I=1$ and for $I=-1$, and since $N$ is positive for $I=0$ and is of the second degree in $I$, it follows that $N$ is negative for all integral values of $I$ except $I=0$, for otherwise the equation $N=0$ would have more than two roots for real values of $I$. Hence $F$ is prime by Theorem $\mathrm{I}$.

EXAMPle 3. Let $A=6, B=1$, and $C=31$. Then from Theorem III: $F=\left(6 X^{2}+6 X Y+31 Y^{2}\right) /(6, Y)$ is a prime when $(X, Y)=1$ and $Y \neq 0$ and:

$$
31-\frac{(Y+6)^{2}}{24}>X>\frac{(Y-6)^{2}}{24}-31 .
$$

[(13) follows in a simple way from (12).] It can be seen from (13) that the limits are parabolas. There are 309 different values of $F$ within the limits (13); see Fig. 1, where each prime is represented by four symmetrically placed points $(X, Y)$, corresponding to the four representations of a prime $F$ by $[6 / E, 6,31 E] .[F=59$ is an exception, since 59 divides $D$.$] Every lattice point within the limits (13)$ and with $(X, Y)=1$ is marked, and the parabolas found by placing equals signs in (13) are shown in the figure.

ExAMPLe 4 . Replace $X$ by $X Y+1$ in all the formulas of Example 3. The result can be seen in Fig. 2; the limits have become 
hyperbolas, and every lattice point with $Y \neq 0$ and within the limits corresponds to a prime. Some of the primes of Fig. 1 are lost by the transformation, but 150 distinct primes remain.

\section{REFERENCE}

A number of references are given in Dickson's "History of the Theory of Numbers", Vol. I, Pages $420,421$.

Received March 7, 1968. 



\title{
PACIFIC JOURNAL OF MATHEMATICS
}

\author{
EDITORS
}

\author{
H. SAMelson \\ Stanford University \\ Stanford, California 94305 \\ C. R. HoBBy \\ University of Washington \\ Seattle, Washington 98105
}

J. DugunduI

Department of Mathematics

University of Southern California

Los Angeles, California 90007

RICHARD ARENS

University of California

Los Angeles, California 90024

\section{ASSOCIATE EDITORS}

\author{
E. F. BeCKENBACH
}

B. H. NEUMANN

F. WoLF

K. YOSHIDA

\section{SUPPORTING INSTITUTIONS}

\author{
UNIVERSITY OF BRITISH COLUMBIA \\ CALIFORNIA INSTITUTE OF TECHNOLOGY \\ UNIVERSITY OF CALIFORNIA \\ MONTANA STATE UNIVERSITY \\ UNIVERSITY OF NEVADA \\ NEW MEXICO STATE UNIVERSITY \\ OREGON STATE UNIVERSITY \\ UNIVERSITY OF OREGON \\ OSAKA UNIVERSITY \\ UNIVERSITY OF SOUTHERN CALIFORNIA
}

\author{
STANFORD UNIVERSITY \\ UNIVERSITY OF TOKYO \\ UNIVERSITY OF UTAH \\ WASHINGTON STATE UNIVERSITY \\ UNIVERSITY OF WASHINGTON \\ AMERICAN MATHEMATICAL SOCIETY \\ CHEVRON RESEARCH CORPORATION \\ NAVAL WEAPONS CENTER
}

The Supporting Institutions listed above contribute to the cost of publication of this Journal, but they are not owners or publishers and have no responsibility for its content or policies.

Mathematical papers intended for publication in the Pacific Journal of Mathematics should be in typed form or offset-reproduced, (not dittoed), double spaced with large margins. Underline Greek letters in red, German in green, and script in blue. The first paragraph or two must be capable of being used separately as a synopsis of the entire paper. The editorial "we" must not be used in the synopsis, and items of the bibliography should not be cited there unless absolutely necessary, in which case they must be identified by author and Journal, rather than by item number. Manuscripts, in duplicate if possible, may be sent to any one of the four editors. Please classify according to the scheme of Math. Rev. Index to Vol. 39. All other communications to the editors should be addressed to the managing editor, Richard Arens, University of California, Los Angeles, California, 90024.

50 reprints are provided free for each article; additional copies may be obtained at cost in multiples of 50 .

The Pacific Journal of Mathematics is published monthly. Effective with Volume 16 the price per volume (3 numbers) is $\$ 8.00$; single issues, $\$ 3.00$. Special price for current issues to individual faculty members of supporting institutions and to individual members of the American Mathematical Society: $\$ 4.00$ per volume; single issues $\$ 1.50$. Back numbers are available.

Subscriptions, orders for back numbers, and changes of address should be sent to Pacific Journal of Mathematics, 103 Highland Boulevard, Berkeley, California, 94708.

PUBLISHED BY PACIFIC JOURNAL OF MATHEMATICS, A NON-PROFIT CORPORATION

Printed at Kokusai Bunken Insatsusha (International Academic Printing Co., Ltd.), 7-17, Fujimi 2-chome, Chiyoda-ku, Tokyo, Japan. 


\section{Pacific Journal of Mathematics}

\section{Vol. 37, No. $3 \quad$ March, 1971}

Mohammad Shafqat Ali and Marvin David Marcus, On the degree of the

minimal polynomial of a commutator operator ................ 561

Howard Anton and William J. Pervin, Integration on topological

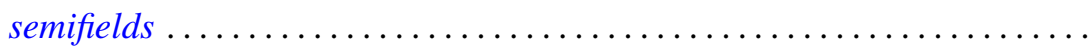

Martin Bartelt, Multipliers and operator algebras on bounded analytic

functions .................................... 575

Donald Earl Bennett, Aposyndetic properties of unicoherent continua ...... 585

James W. Bond, Lie algebras of genus one and genus two ............. 591

Mario Borelli, The cohomology of divisorial varieties ............... 617

Carlos R. Borges, How to recognize homeomorphisms and isometries ....... 625

J. C. Breckenridge, Burkill-Cesari integrals of quasi additive interval

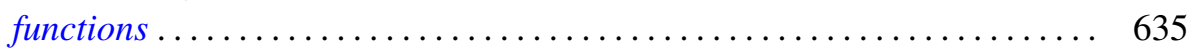

J. Csima, A class of counterexamples on permanents ................ 655

Carl Hanson Fitzgerald, Conformal mappings onto $\omega$-swirly domains . . . . . . 657

Newcomb Greenleaf, Analytic sheaves on Klein surfaces .............. 671

G. Goss and Giovanni Viglino, C-compact and functionally compact

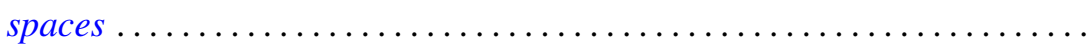

Charles Lemuel Hagopian, Arcwise connectivity of semi-aposyndetic plane

continua ..................................... 683

John Harris and Olga Higgins, Prime generators with parabolic limits ...

David Michael Henry, Stratifiable spaces, semi-stratifiable spaces, and their

relation through mappings .......................

Raymond D. Holmes, On contractive semigroups of mappings ........... 701

Joseph Edmund Kist and P. H. Maserick, BV-functions on semilattices ....... 711

Shûichirô Maeda, On point-free parallelism and Wilcox lattices ........... 725

Gary L. Musser, Linear semiprime $(p ; q)$ radicals ................. 749

William Charles Nemitz and Thomas Paul Whaley, Varieties of implicative

semilattices..................................... 759

Jaroslav Nešetřil, A congruence theorem for asymmetric trees ............ 771

Robert Anthony Nowlan, A study of $H$-spaces via left translations .......... 779

Gert Kjærgaard Pedersen, Atomic and diffuse functionals on a $C^{*}$-algebra ... 795

Tilak Raj Prabhakar, On the other set of the biorthogonal polynomials

suggested by the Laguerre polynomials...

801

Leland Edward Rogers, Mutually aposyndetic products of chainable

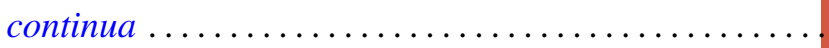

Frederick Stern, An estimate for Wiener integrals connected with squared

error in a Fourier series approximation.

Leonard Paul Sternbach, On k-shrinking and k-boundedly complete basic

sequences and quasi-reflexive spaces .................... 817

Pak-Ken Wong, Modular annihilator $A^{*}$-algebras ........ 